\title{
Publisher's Note: Evidence of a halo formation mechanism in the Spallation Neutron Source linac [Phys. Rev. ST Accel. Beams 16, 040103 (2013)]
}

\author{
Dong-O Jeon \\ (Received 14 May 2013; published 17 May 2013) \\ PACS numbers: 41.85.Si, 41.75.-i, 29.27.-a, 99.10.Fg
}

DOI: 10.1103/PhysRevSTAB.16.059901

This paper was published online on 23 April 2013 with an incorrect affiliation. The author affiliation has been corrected as of 16 May 2013.

Published by the American Physical Society under the terms of the Creative Commons Attribution 3.0 License. Further distribution of this work must maintain attribution to the author(s) and the published article's title, journal citation, and DOI. 